\title{
Pistacia chinensis Methanolic Extract Attenuated MAPK and Akt Phosphorylations in ADP Stimulated Rat Platelets In Vitro
}

\author{
Ji Young Park, ${ }^{1}$ Mei Hong, ${ }^{2}$ Qi Jia, ${ }^{2}$ Young-Chul Lee, ${ }^{2}$ Taddesse Yayeh, ${ }^{1}$ Eujin Hyun, ${ }^{2}$ \\ Dong-Mi Kwak, ${ }^{1}$ Jae Youl Cho, ${ }^{3}$ and Man Hee Rhee ${ }^{1}$
}

\author{
${ }^{1}$ Department of Veterinary Medicine, College of Veterinary Medicine and Stem Cell Research Therapeutic Institute, \\ Kyungpook National University, Daegu 702-701, Republic of Korea \\ ${ }^{2}$ Unigen Inc., Chungnam, Cheonan 330-863, Republic of Korea \\ ${ }^{3}$ Department of Genetic Engineering, Sungkyunkwan University, Suwon 440-746, Republic of Korea
}

Correspondence should be addressed to Jae Youl Cho, jaecho@skku.edu and Man Hee Rhee, rheemh@knu.ac.kr

Received 13 February 2012; Revised 13 June 2012; Accepted 20 June 2012

Academic Editor: Carlo Ventura

Copyright () 2012 Ji Young Park et al. This is an open access article distributed under the Creative Commons Attribution License, which permits unrestricted use, distribution, and reproduction in any medium, provided the original work is properly cited.

\begin{abstract}
Pistacia chinensis (Chinese pistache) is a widely grown plant in southern China where the galls extract is a common practice in folk medicine. However, extracts from this plant have never been attempted for their cardiovascular protective effects in experimental setting. Here therefore we aimed to investigate the antiplatelet activity of Pistacia chinensis methanolic extract (PCME) in ADP stimulated rat platelets in vitro. PCME $(2.5-20 \mu \mathrm{g} / \mathrm{mL})$ inhibited ADP-induced platelet aggregation. While PCME diminished $\left[\mathrm{Ca}^{2+}\right] i$, ATP, and TXA2 release in ADP-activated platelets, it enhanced cAMP production in resting platelets. Likewise, PCME inhibited fibrinogen binding to $\alpha \operatorname{IIb} \beta 3$ and downregulated JNK, ERK, and Akt phosphorylations. Thus, PCME contains potential antiplatelet compounds that could be deployed for their therapeutic values in cardiovascular pathology.
\end{abstract}

\section{Introduction}

Platelets adhere and mitigate bleeding during vascular injury through plug formation [1]; nevertheless, their dysfunctions gear toward thrombus development and subsequent cardiovascular pathology [2]. At the injured vascular site, the exposed subendothelial collagen and von Willebrand factor (vWF) initiate platelet activation marked by the secretion of prothrombotic factors like ADP, thrombin, serotonin, and thromboxane A2 (TXA2) [3]. Platelet activation is also further amplified by dense granule secretions (ADP and ATP) and $\alpha$-granule adhesive molecules like fibrinogen and $P$-selectin [4].

ADP activates G-protein-coupled receptor (GPCR) signaling mediated by two metabotropic purinergic receptors in platelets, Gq-coupled $\mathrm{P}_{2} \mathrm{Y}_{1}$ receptor activates phospholipase $\mathrm{C} \beta$ whereas Gi-coupled $\mathrm{P} 2 \mathrm{Y}_{12}$ receptor inhibits adenylyl cyclase and activates PI-3K/Akt and ERK [5]. Adenylyl cyclase enhances cyclic adenosine monophosphoate (cAMP) which activates protein kinase (PKA) that inhibits platelet shape change, granule secretion, calcium mobilization, and aggregation [6]. However, ADP-induced adenylyl cyclase attenuation vanishes cAMP production which culminate in platelet activation. Likewise, ADP-stimulated Gi-coupled $\mathrm{P} 2 \mathrm{Y} 12$ receptor that activates mitogen-activated protein kinases (MAPKs) (ERK, JNK, and p38) and PI-3k/Akt signaling to arrive at similar scenario of platelet activation and aggregation [7].

Pistacia chinensis (chinese pistache) is a drought resistance deciduous indigenous tree in southern China. The tree is marked by its finely divided dark green foliage with an attractive orange bark which has been used frequently for grafting the commercial Pistacia vera [8] that showed antiatherosclerosis [9], anti-inflammatory [10], and antioxidant effects [11]. Nevertheless, the antiplatelet activity of Pistacia chinensis was unattempted yet. We therefore reported that Pistacia chinensis methanolic extract (PCME) inhibited ADP stimulated rat platelet granule secretions and aggregation in vitro. Furthermore, PCME attenuated ERK, JNK, and Akt phosphorylations in ADP-stimulated platelets, while it enhanced CAMP production. 
TABle 1: List of chemicals identified in PCME using GC-mass spectrometry.

\begin{tabular}{lc}
\hline Name of compound & $(\%)$ \\
\hline Methane & 66.4 \\
DMSO & 11.4 \\
Dichloroethylene & 1.1 \\
Resorcinol & 18.9 \\
Pyridine & 2.2 \\
\hline
\end{tabular}

\section{Materials and Methods}

2.1. Materials. Fura-2/AM was obtained from Sigma (St. Louis, MO, USA). ADP was procured from Chrono-log (Havertown, PA, USA). Antibodies against phospho-p44/42, p44/42, phospho-p38, p38, phospho-SAPK/JNK, and $\beta$ actin were bought from Cell Signaling (Beverly, MA, USA). ATP assay kits were purchased from Biomedical Research Service Center (Buffalo, NY, USA). TXB2 EIA was purchased from Enzo Life Sciences (Plymouth Meeting, PA, USA). cAMP enzyme immunoassay (EIA) kits were from Cayman Chemical (MI, USA). Fibrinogen Alexa Fluor 488 conjugate was obtained from Invitrogen molecular probes (Eugene, OR, USA). All other chemicals were of reagent grade.

2.2. Sample Preparation and GC Mass Spectrometry Analysis. Dr. Zhengliu Zhang identified Pistacia chinensis trunk bark collected from Sichuan, China and the voucher specimen (PLSA1301) was deposited at the Unigen Inc., till the extraction date. Trunk bark of Pistacia chinensis was dried and pulverized into powder, of which $159 \mathrm{~g}$ with $50 \%$ methanol/dichloromethane (MeOH/DCM) extraction yielded $11 \mathrm{~g}$ for silica gel fractionation to get $590 \mathrm{mg}$ of subfraction. $300 \mathrm{mg}$ of $500 \mathrm{mg}$ was again further purified by preparative HPLC (Luna C18, $30 \times 250 \mathrm{~mm}$ ) to obtain $30 \mathrm{mg}$ of fraction. PCME of the final fraction $(2.5 \mathrm{mg})$ was employed in GC mass analysis indicating its polyphenolic nature replete with resorcinol (18.9\%) and pyridine $(2.8 \%)$ compounds with common structural moieties (Table 1 and Figure 1) except solvents like methane, DMSO, and dichloroethylene. GC mass spectrometry was performed using Agilent Technology 7890A-Gas Chromatograph system (Agilent Technologies, Santa Clara, CA, USA), coupled to XLMSD-5975C equipment operating in electrospray ionisation (EI) mode.

2.3. Platelet Preparation and Aggregation Assay. Platelets preparations from rats were described previously [12]. Briefly, 8 weeks old male Sprague Dawely rats (240-250 g weight) were obtained from Orient Co. (Seoul, Korea) and maintained in a standard laboratory facility with ad libitum feed and water. Whole blood was collected using a $23 \mathrm{G}$ needle from abdominal aorta and then transferred into $15 \mathrm{~mL}$ test tube containing $1 \mathrm{~mL}$ of the anticoagulant acid/citrate/dextrose (ACD, $85 \mathrm{mM}$ trisodium citrate, $83 \mathrm{mM}$ dextrose, and $21 \mathrm{mM}$ citric acid). Blood was centrifuged at $170 \times \mathrm{g}$ for $7 \mathrm{~min}$ to obtain platelet-rich plasma which was<smiles>Oc1cccc(O)c1</smiles>

(a) resorcinol<smiles>Oc1ccc(/C=C/c2cc(O)cc(O)c2)cc1</smiles>

(b) resveratrol<smiles>O=c1c(O)c(-c2ccc(O)c(O)c2)oc2cc(O)cc(O)c12</smiles>

(c) quercetin<smiles>Oc1cc(O)c2c(c1)O[C@H](c1ccc(O)c(O)c1)[C@H](O)C2</smiles>

(d) catechin

FIGURE 1: Structural analysis of major chemical compounds available in PCME.

further centrifuged at $120 \times \mathrm{g}$ for $7 \mathrm{~min}$ to remove residual erythrocytes. This platelet-rich plasma was centrifuged twice at $350 \times \mathrm{g}$ with a washing buffer for $10 \mathrm{~min}$ to remove the ACD solution, and then platelet precipitates were adjusted to $\left(3 \times 10^{8} / \mathrm{mL}\right)$ for aggregation assay in Tyrode buffer ( $137 \mathrm{mM}$ of $\mathrm{NaCl}, 12 \mathrm{mM}$ of $\mathrm{NaHCO}_{3}, 5.5 \mathrm{mM}$ of glucose, $2 \mathrm{mM}$ of $\mathrm{KCl}, 1 \mathrm{mM}$ of $\mathrm{MgCl}_{2}, 0.3 \mathrm{mM}$ of $\mathrm{NaHPO}_{4}$, and $\mathrm{pH}$ 7.4). All platelet preparations were conducted at room temperature, and all experimental procedures and protocols used in this investigation were reviewed and approved by the Ethics Committee of the College of Veterinary Medicine, Kyungpook National University.

Platelet aggregation was conducted as mentioned before. Briefly, aggregation was monitored by measuring light 
transmission in an aggregometer (Chronolog, Havertown, PA, USA). The washed platelets were preincubated at $37^{\circ} \mathrm{C}$ for 2 min with either PCME or vehicle $(<0.1 \%)$, and then stimulated with agonists. The reaction mixture was further incubated for $5 \mathrm{~min}$, stirring at $170 \times \mathrm{g}$.

2.4. Determining $\left[\mathrm{Ca}^{2+}\right] i$. The $\left[\mathrm{Ca}^{2+}\right] i$ was determined with Fura-2/AM as described previously [13]. Briefly, platelets were incubated with $5 \mu \mathrm{M}$ of Fura-2/AM for $30 \mathrm{~min}$ at $37^{\circ} \mathrm{C}$ and washed. The Fura-2-loaded platelets $\left(3 \times 10^{8} / \mathrm{ml}\right)$ were then pre-incubated with PCME for $3 \mathrm{~min}$ at $37^{\circ} \mathrm{C}$ in the presence of $1 \mathrm{mM} \mathrm{CaCl}$, then stimulated with ADP for $5 \mathrm{~min}$. Fluorescence signals were recorded using a Hitachi F-2500 fluorescence spectrofluorometer (F-2500, Hitachi, Japan). Fluorescence emission was determined at $510 \mathrm{~nm}$, with simultaneous excitation at 340 and $380 \mathrm{~nm}$, changing every $0.5 \mathrm{~s}$. Fura-2 fluorescence was measured in a spectrofluorometer by the method of Schaeffer: $\left[\mathrm{Ca}^{2+}\right] i$ in cytosol $=224 \mathrm{nM} \times\left(F-F_{\min }\right) /\left(F_{\max }-F\right)$, where $224 \mathrm{nM}$ is the dissociation constant of the Fura-2-Ca ${ }^{2+}$ complex, and $F_{\min }$ and $F_{\max }$ represent the fluorescence intensity levels at very low and very high $\mathrm{Ca}^{2+}$ concentrations, respectively. In our experiment, $F_{\max }$ is the fluorescence intensity of the Fura-2- $\mathrm{Ca}^{2+}$ complex at $510 \mathrm{~nm}$ after the platelet suspension containing $1 \mathrm{mM}$ of $\mathrm{CaCl}_{2}$ had been solubilized by Triton $\mathrm{X}-100(0.1 \%) . F_{\min }$ is the fluorescence intensity of the Fura$2-\mathrm{Ca}^{2+}$ complex at $510 \mathrm{~nm}$, after the platelet suspension containing $20 \mathrm{mM}$ Tris/ $3 \mathrm{mM}$ of EGTA had been solubilized by Triton X-100 (0.1\%). F represents the fluorescence intensity of the Fura-2-complex at $510 \mathrm{~nm}$ after the platelet suspension was stimulated by ADP, with and without PCME, in the presence of $1 \mathrm{mM} \mathrm{CaCl}_{2}$.

2.5. ATP Release Assay. Washed platelets were pre-incubated for $2 \mathrm{~min}$ at $37^{\circ} \mathrm{C}$ with various concentrations of PCME and then platelets were stimulated with ADP for 5 min. After the reaction was terminated, samples were centrifuged and supernatants were used for ATP assay in a luminometer (GloMax 20/20, Promega, Madison, USA) using an ATP assay kit (Biomedical Research Service Center, Buffalo, USA).

2.6. Determination of Thromboxane A2 Generation. Washed platelets $\left(3 \times 10^{8} / \mathrm{ml}\right)$ were pre-incubated with or without PCME for $2 \mathrm{~min}$ in the presence of $1 \mathrm{mM} \mathrm{CaCl}_{2}$, and then the platelets were stimulated with ADP. Reactions were terminated after $5 \mathrm{~min}$ by adding ice-cold $2.5 \mathrm{mM}$ EDTA and $100 \mu \mathrm{M}$ indomethacin. After centrifugation at $14,000 \mathrm{rpm}$ for 3 min at $4^{\circ} \mathrm{C}$, the amount of TXB2 (supernatant) was determined using TXB2 EIA kit according to the manufacturer's protocol (Enzo Life Sciences, Plymouth Meeting, PA, USA).

2.7. Measurements of cAMP. Washed platelets were preincubated for $2 \mathrm{~min}$ at $37^{\circ} \mathrm{C}$ with various concentrations of PCME or vehicle in the presence of $1 \mathrm{mM} \mathrm{CaCl}_{2}$, and then stimulated with ADP for $5 \mathrm{~min}$ in a platelet aggregometer. The reaction was terminated by the addition of equal volumes of $80 \%$ ice-cold ethanol. Samples were then centrifuged at 2,000 $\times \mathrm{g}$ for $10 \mathrm{~min}$ at $4^{\circ} \mathrm{C}$ and the supernatant cAMP level was determined with a cyclic AMP (Ann Arbor, MI, USA).

2.8. Immunoblotting. Proteins were prepared as previously described [14]. Briefly, platelet suspensions $\left(3 \times 10^{8} / \mathrm{mL}\right)$ were pre-incubated with PCME or vehicle. Platelet activation was induced by ADP and the reaction was allowed to proceed for $5 \mathrm{~min}$. After termination of the reaction, lysates were prepared by solubilizing and centrifuging platelets in sample buffer $(0.125 \mathrm{M}$ Tris- $\mathrm{HCl}$ at $\mathrm{pH} 6.8,2 \% \mathrm{SDS}, 2 \% \beta$ mercaptoethanol, $20 \%$ glycerol, and $0.02 \%$ bromophenol blue) in the presence of protease inhibitors $(\mu \mathrm{g} / \mathrm{ml}: 1$ phenylmethylsulfonylfluoride (PMSF), 2 aprotinin, 1 leupeptin, and 1 pepstatin A). Protein concentration was determined using BCA Assay (PRO-MEASURE, iNtRON Biotechnology, Korea). $30 \mu \mathrm{g}$ of protein was separated in 10\% SDS-PAGE and transferred to nitrocellulose membrane in transfer buffer (25 mM Tris ( $\mathrm{pH} 8.5$ ), $0.2 \mathrm{M}$ glycine, and 20\% methanol). Immunoblots were blocked with TBS-T containing 5\% non-fat dry milk, washed, and incubated with primary antibody diluted in a blocking solution. The immunoblots were again probed with horseradish peroxidase secondary antibody, and membranes were visualized using enhanced chemiluminescence, ECL (iNtRON Biotechnology, Korea).

2.9. Fibrinogen-Binding Assay. Alexa Fluor 488-fibrinogen binding to the washed platelets was quantified by flow cytometry. Briefly, the washed platelets were pre-incubated with PCME at room temperature in the presence of $0.1 \mathrm{mM}$ $\mathrm{CaCl}_{2}$. The platelets were then stimulated by ADP for $5 \mathrm{~min}$, and immediately incubated with Alexa Fluor 488human fibrinogen $(20 \mu \mathrm{g} / \mathrm{mL})$ for $5 \mathrm{~min}$ and fixed with $0.5 \%$ paraformaldehyde at $4{ }^{\circ} \mathrm{C}$ for $30 \mathrm{~min}$. Platelets were pelleted by centrifugation at $2000 \times \mathrm{g}$ at $4^{\circ} \mathrm{C}$ and resuspended in $500 \mu \mathrm{L}$ PBS. Binding of fibrinogen to integrin $\alpha_{\mathrm{IIb}} \beta_{3}$ was measured in the presence of calcium chelator EGTA $1 \mathrm{mM}$. Fluorescent intensities were determined using FACS Calibur cytometer (BD Biosciences, San Jose, UAS), and data were analyzed using CellQuest software (Becton Dickinson Immunocytometry Systems, San Jose, CA).

2.10. Statistical Analysis. One-way analysis of variance was used for data analysis followed by a post hoc Dunnett's test for statistical significance. All data were means \pm S.E.M. $P$ values less than 0.05 were considered statistically significant.

\section{Results}

3.1. PCME Inhibited ADP-Induced Platelet Aggregation. ADP is a well-known soluble agonist for platelet aggregation and thrombus formation [2]. Previously, we showed that ADP at $10 \mu \mathrm{M}$ induced complete platelet aggregation and, therefore, this concentration was used to induce platelet aggregation in this study. PCME $(5-20 \mu \mathrm{g} / \mathrm{mL})$ showed a dose dependent inhibition of ADP $(10 \mu \mathrm{M})$ induced platelet aggregation in rat platelets with a potent effect observed at the highest dosage $(20 \mu \mathrm{g} / \mathrm{mL})$ used (Figure 2$)$. 


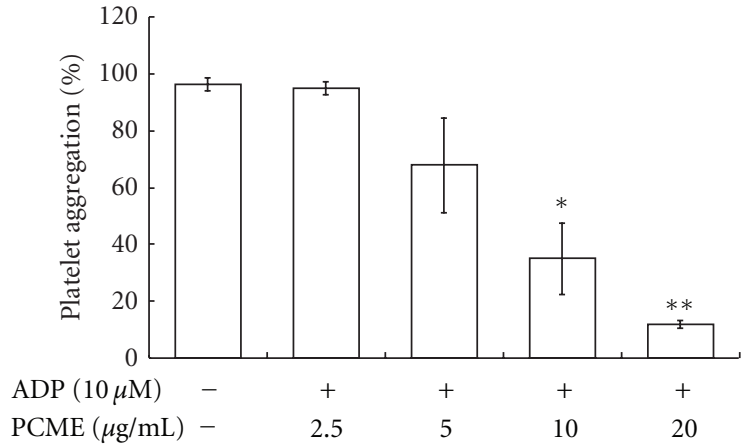

FIgure 2: The inhibitory effect of PCME in ADP-induced platelet aggregation. Platelets $\left(3 \times 10^{8} / \mathrm{ml}\right)$ were preincubated with or without PCME in the presence of $1 \mathrm{mM} \mathrm{CaCl}_{2}$ for $3 \mathrm{~min}$ at $37^{\circ} \mathrm{C}$ and then stimulated with $10 \mu \mathrm{M}$ ADP. Agonist-induced platelet aggregation was terminated at $5 \mathrm{~min}$, and then percent aggregation rate was determined. Each graph shows mean \pm SEM from 4 independent experiments performed. ${ }^{*} P<0.05$ and ${ }^{* *} P<0.01$ were considered as statistically significant compared with agonist control.

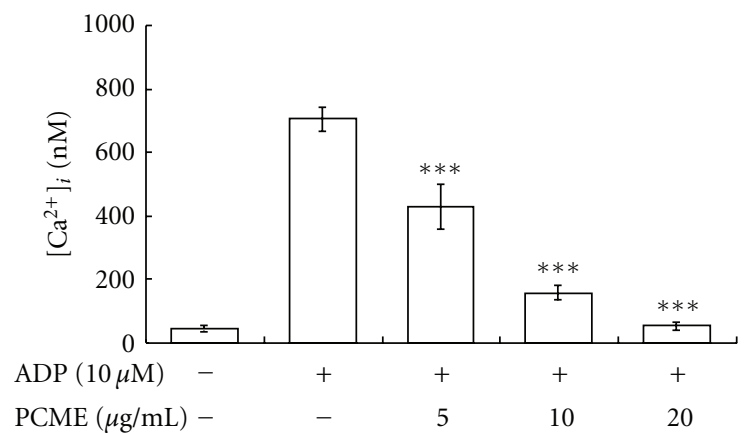

(a)

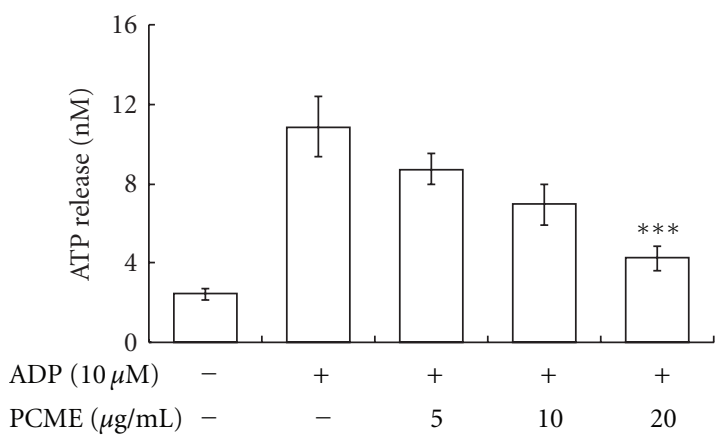

(b)

FIgure 3: Inhibitory effect of PCME on ADP-induced $\left[\mathrm{Ca}^{2+}\right] i$ mobilization and ATP release. Washed platelets were incubated with calcium fluorophore (fura-2/AM) and then stimulated with ADP as described in Section 2 for $\left[\mathrm{Ca}^{2+}\right] i$ determination (a). For ATP assay (b), washed platelets were pre-incubated with PCME, stirred in an aggregometer for $3 \mathrm{~min}$ and then stimulated with ADP for $5 \mathrm{~min}$. Each graph shows mean \pm SEM from 3 independent experiments performed. ${ }^{* * *} P<0.01$ was considered as statistically significant compared with agonist control.

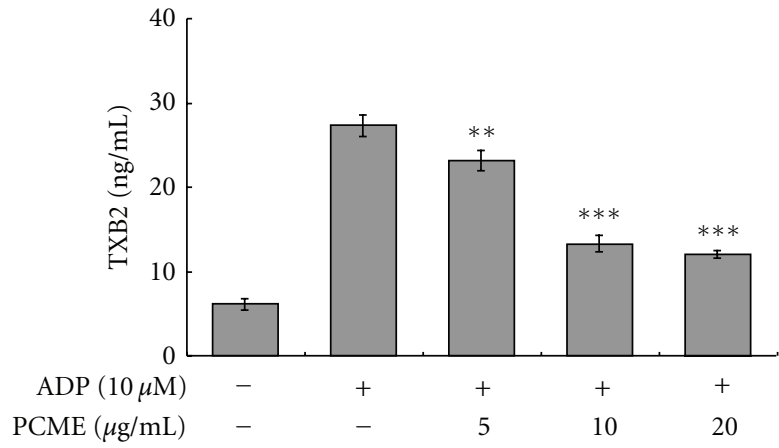

(a)

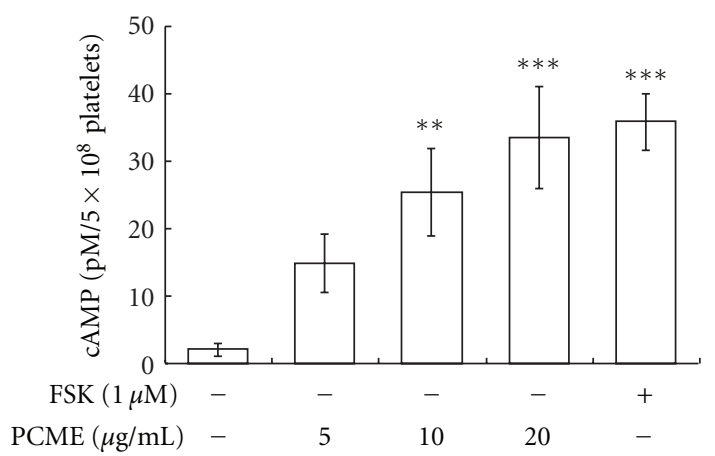

(b)

FIgURE 4: Effect of PCME on TXA2 generation and cAMP production. ADP $(10 \mu \mathrm{M})$ evoked TXB2 production (as measure of TXA2 generation) which was measured after $5 \mathrm{~min}$ of ADP stimulation according to EIA Kit instructions (a). For cAMP assay (b), washed platelets were stirred with vehicle, PCME, or forskolin in an aggregometer prior to ADP stimulation for $5 \mathrm{~min}$. Reaction was terminated, and then cAMP enzyme immunoassay was performed as described in Section 2. Bar graphs show mean \pm SEM of 3 independent experiments performed. ${ }^{* *} P<0.01$ and ${ }^{* * *} P<0.005$ considered as statistically significant compared with control.

3.2. PCME Attenuated ADP-Induced $\left[\mathrm{Ca}^{2+}\right] \mathrm{i}$ Elevation and ATP Release. Platelet activation is marked by the release of platelet granular contents. Therefore, we determined whether PCME used at various concentrations attenuated the release of $\left[\mathrm{Ca}^{2+}\right] i$ and ATP from dense granules in platelets stimulated with ADP. PCME (5-20 $\mu \mathrm{g} / \mathrm{mL})$ strongly diminished $\left[\mathrm{Ca}^{2+}\right] i$ mobilization (Figure 3(a)), and the same inhibitory effect on ATP release was observed at a lesser degree (Figure 3(b)).

\subsection{The Effect of PCME on TXA2 and cAMP Generation} in ADP-Activated Platelets. While thromboxane A2 (TXA2) is an important mediator in the amplification of platelet activation, cAMP plays an imperative role in antiplatelet activity. Therefore, we measured the intracellular level of ADP-induced TXA2 generation and the level of cAMP in unstimulated platelets pretreated with PCME in vitro. PCME $(5-20 \mu \mathrm{g} / \mathrm{mL})$ markedly inhibited the stable form of TXA2 (i.e., TXB2) in ADP-stimulated platelets (Figure 4(a)) whereas the level of cAMP was profoundly upregulated and 


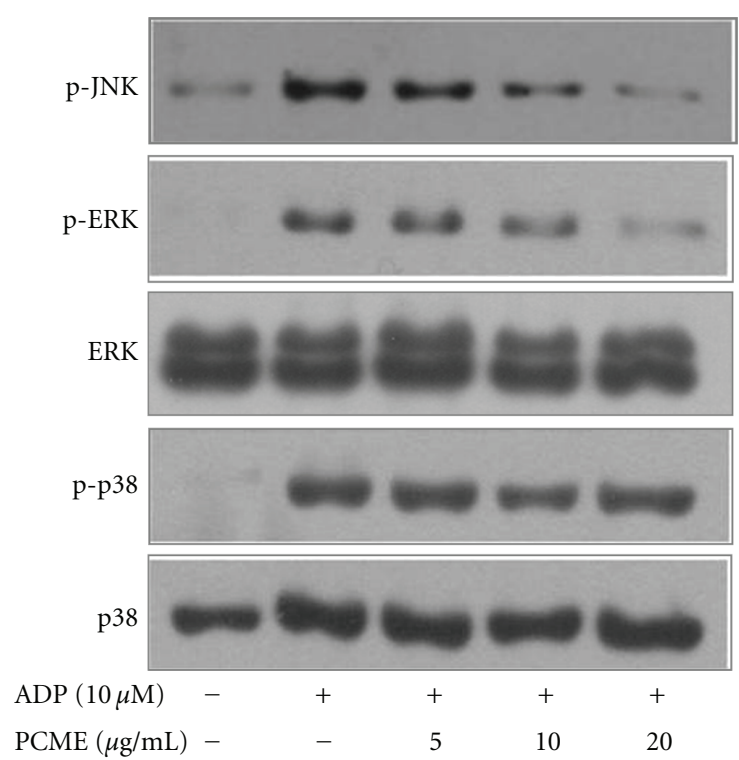

(a)

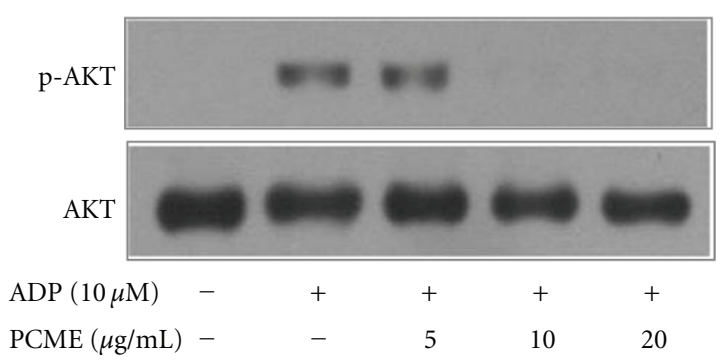

(b)

Figure 5: Effects of PCME on ADP-induced MAPK and Akt phosphorylations. Washed platelets were stirred in an aggregometer with vehicle or PCME for $3 \mathrm{~min}$ and then stimulated with ADP for $5 \mathrm{~min}$. Reaction was terminated and proteins were extracted, separated by SDS-PAGE, blotted onto PVDF membrane and probed using antibodies against phospho- and total (JNK, ERK, p38) (a); and phospho- and total Akt (b). Bands represented triplicate of independent experiments.

its level at the highest concentration of PCME $(20 \mu \mathrm{g} / \mathrm{mL})$ was comparable with that of forskolin used at $1 \mu \mathrm{M}$ (Figure $4(\mathrm{~b}))$.

3.4. PCME Attenuated JNK, ERK, and Akt Phosphorylations in ADP-Induced Platelets. Phosphorylations of mitogenactivated protein kinases (MAPKs) (ERK, p38, and JNK) and Akt in platelets are closely associated with platelet activation and aggregation. Hence, we determined if PCME inhibited MAPK and Akt phosphorylations in ADP stimulated platelets. Whereas p38 phosphorylation was unaffected by PCME (5-20 $\mu \mathrm{g} / \mathrm{mL})$, ERK and JNK phosphorylations were dose-dependently suppressed in ADP-activated platelets (Figure 5(a)). Moreover, PCME totally demolished phosphorylation of Akt beyond $5 \mu \mathrm{g} / \mathrm{ml}$ of concentration (Figure 5(b)).

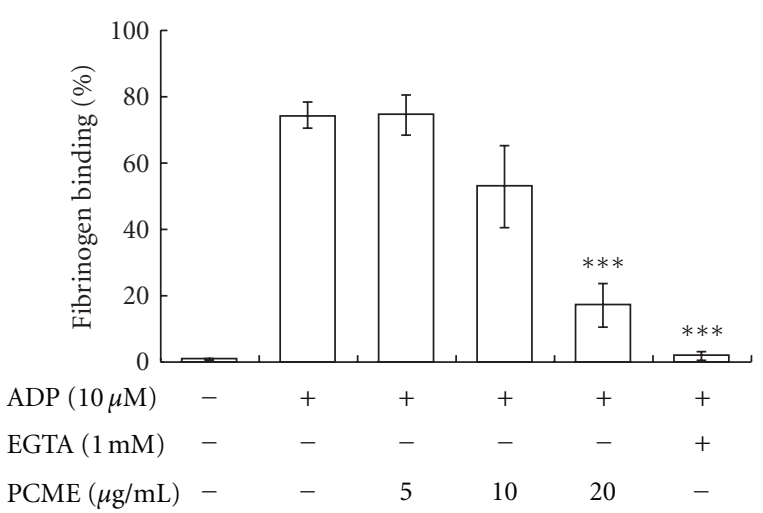

(a)

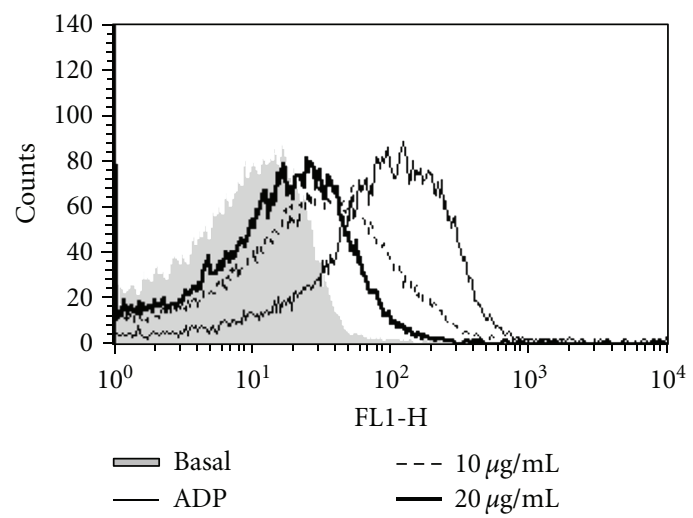

(b)

FIGURE 6: Effects of PCME on fibrinogen binding to integrin $\alpha_{\mathrm{II}} \beta_{3}$ in ADP-activated platelets. Washed platelets were pretreated with PCME at 10 and $20 \mu \mathrm{g} / \mathrm{mL}$, and then stimulated with ADP $(10 \mu \mathrm{M})$ in Alexa Fluor 488-human fibrinogen $(20 \mu \mathrm{g} / \mathrm{mL})$ for $5 \mathrm{~min}$, fixed with $0.5 \%$ paraformaldehyde at $4^{\circ} \mathrm{C}$ for $30 \mathrm{~min}$. Fluorescent intensity graphs indicate 4 independent experiments (a). Data exhibit mean fluorescence intensity (MFI) of fibrinogenpositive platelets. Each graph was expressed as $\%$ of gated (b). ${ }^{* *} P<$ 0.01 and ${ }^{* * *} P<0.005$ were considered as statistically significant compared with agonist.

3.5. PCME Inhibited Fibrinogen Binding to Integrin $\alpha_{I I b} \beta_{3}$ in ADP-Activated Platelets. Integrin activation and the subsequent fibrinogen binding to $\alpha_{\mathrm{IIb}} \beta_{3}$ are crucial events in platelet aggregation. Thus, we determined whether fibrinogen binding to integrin $\alpha_{\mathrm{IIb}} \beta_{3}$ was inhibited in platelets pretreated with PCME and stimulated by ADP. Our finding revealed that PCME at 10 and $20 \mu \mathrm{g} / \mathrm{mL}$ inhibited fibrinogen binding to activated integrin $\alpha_{\mathrm{II}} \beta_{3}$ in ADP-stimulated rat platelets (Figures 6(a) and 6(b)).

\section{Discussion}

In this study, we reported that Pistacia chinensis methanolic extract (PCME) displayed broad inhibitory effects on platelet aggregation, calcium mobilization, ATP release, TXA2 formation, and fibrinogen binding to $\alpha_{\mathrm{IIb}} \beta_{3}$ in ADP-activated platelets. Moreover, PCME enhanced cAMP production 
in unstimulated platelets whereas it downregulated ADPstimulated ERK, JNK, and Akt phosphorylations.

ADP activates two G-protein-coupled purinoceptors, $\mathrm{P} 2 \mathrm{Y}_{12}$ and $\mathrm{P} 2 \mathrm{Y}_{1}$, to transduce its intracellular signaling [15]. $\mathrm{P} 2 \mathrm{Y}_{1}$ receptor is linked to Gq to activate $\mathrm{PLC} \beta$ with consequent formation of inositol-1,4,5-trisphosphate (IP3) and $\mathrm{Ca}^{2+}$ release in one side and 1,2-diacylglycerol required for protein kinase $\mathrm{C}(\mathrm{PKC})$ activation on the other. $\mathrm{P}_{2} \mathrm{Y}_{12}$ receptor is linked to the adenylate cyclase inhibiting Gi-protein [16]. Here, therefore, we explored that PCME inhibited the rise of $\left[\mathrm{Ca}^{2+}\right] i$ in ADP stimulated platelets (Figure 3(a)) while it upregulated the level of cAMP in resting platelets (Figure 4(b)), suggesting that ADP receptors could be among the potential targets of PCME via upregulation of CAMP which has been reviewed as inhibitor of G-protein-coupled receptors [17], albeit this needs further insightful verification. Likewise, previous reports indicated that resorcinol showed antiplatelet activity [18] mediated through COX-1 inhibition [19], implicating that the diminished release of TXA2 (Figure 4(a)) at this moment might be originated from a similar effect of resorcinol available in PCME.

Phosphoinositide 3-kinase (PI3K) and Akt play platelet activation via sequential activation of PI-3K/Akt, nitric-oxide synthase 3 , soluble guanylate cyclase (sGC), and cGMPdependent protein kinase [20]. Thus, PCME-mediated inhibition of Akt (Figure 5(b)) may unravel the potential antiplatelet activity of this extract that could be mediated through modulation of PI-3K/Akt/cGMP signaling path-way despite that cGMP has also been reported to inhibit platelet activation [17]. Moreover, a recent report indicated that PI$3 \mathrm{~K} \beta$ plays an important role in ADP-induced ERK activation and TXA2 generation [7], implying that PCME-mediated inhibition of ERK phosphorylation and TXA2 release might indicate its potential target at $\mathrm{P} 2 \mathrm{Y}_{12} / \mathrm{PI}-3 \mathrm{~K} / \mathrm{Akt}$ signaling. Likewise, Adam et al. reported that $\mathrm{NNK}^{-/-}$platelets showed impaired platelet secretion that brought altered integrin $\alpha_{\text {IIb }} \beta_{3}$ activation and reduced platelet aggregation via a mechanism involving PKC [21]. Therefore, we speculated that the reduced fibrinogen binding to $\alpha_{\mathrm{II}} \beta_{3}$ (Figures $6(\mathrm{a})$ and $6(\mathrm{~b})$ ) could be partly attributed to JNK1 inactivation (Figure 5(a)) that might be linked to impaired $\mathrm{P}_{2} \mathrm{Y}_{12-}$ dependent PKC function in PCME pretreated platelets.

We conclude that PCME inhibited ADP-stimulated rat platelet aggregation, JNK, ERK, and Akt phosphorylations. While PCME downregulated TXA2 release and fibrinogen binding to $\alpha_{\mathrm{II}} \beta_{3}$ in activated platelets, it showed enhanced cAMP production at the resting state. Thus, PCME could be considered as a potential antiplatelet agent targeting ADP amplified second wave of platelet secretion and aggregation.

\section{Abbreviations}

PCME: Pistacia chinensis methanolic extract

MAPK: Mitogen-activated protein kinase

TXA2: Thromboxane A2

GPCR: G-protein-coupled receptor

PKA: Protein kinase A

ADP: Adenosine diphosphate
ERK: Extracelluar signal-regulated kinase

JNK: c-jun N-terminal kinase.

\section{Acknowledgments}

This research was supported by a Grant from Ministry of Food, Agriculture, Forestry and Fisheries (110109-03-2HD110), Republic of Korea.

\section{References}

[1] J. M. Gibbins, "Platelet adhesion signalling and the regulation of thrombus formation," Journal of Cell Science, vol. 117, no. 16, pp. 3415-3425, 2004.

[2] R. T. Dorsam and S. P. Kunapuli, "Central role of the $\mathrm{P} 2 \mathrm{Y}_{12}$ receptor in platelet activation," The Journal of Clinical Investigation, vol. 113, no. 3, pp. 340-345, 2004.

[3] J. W. M. Heemskerk, P. R. M. Siljander, E. M. Bevers, R. W. Farndale, and T. Lindhout, "Receptors and signalling mechanisms in the procoagulant response of platelets," Platelets, vol. 11, no. 6, pp. 301-306, 2000.

[4] P. Blair and R. Flaumenhaft, "Platelet $\alpha$-granules: basic biology and clinical correlates," Blood Reviews, vol. 23, no. 4, pp. 177189, 2009.

[5] C. Gachet, "P2Y $\mathrm{Y}_{12}$ receptors in platelets and other hematopoietic and non-hematopoietic cells," Purinergic Signalling, vol. 8, no. 3, pp. 609-619, 2012.

[6] Z. Li, J. Ajdic, M. Eigenthaler, and X. Du, "A predominant role for cAMP-dependent protein kinase in the cGMP-induced phosphorylation of vasodilator-stimulated phosphoprotein and platelet inhibition in humans," Blood, vol. 101, no. 11, pp. 4423-4429, 2003.

[7] S. Kim and S. P. Kunapuli, " $\mathrm{P} 2 \mathrm{Y}_{12}$ receptor in platelet activation," Platelets, vol. 22, no. 1, pp. 54-58, 2011.

[8] L. Yu and J. Lu, "Does landscape fragmentation influence sex ratio of dioecious plants? A case study of Pistacia chinensis in the Thousand-Island lake region of China," PLoS ONE, vol. 6, no. 8, Article ID e22903, 2011.

[9] K. A. Marinou, K. Georgopoulou, G. Agrogiannis et al., "Differential effect of Pistacia vera extracts on experimental atherosclerosis in the rabbit animal model: an experimental study," Lipids in Health and Disease, vol. 9, article 73, 2010.

[10] C. Gentile, M. Allegra, F. Angileri, A. M. Pintaudi, M. A. Livrea, and L. Tesoriere, "Polymeric proanthocyanidins from Sicilian pistachio (Pistacia vera L.) nut extract inhibit lipopolysaccharide-induced inflammatory response in RAW 264.7 cells," European Journal of Nutrition, vol. 51, pp. 353-363, 2011.

[11] A. Tomaino, M. Martorana, T. Arcoraci, D. Monteleone, C. Giovinazzo, and A. Saija, "Antioxidant activity and phenolic profile of pistachio (Pistacia vera L., variety Bronte) seeds and skins," Biochimie, vol. 92, no. 9, pp. 1115-1122, 2010.

[12] D.-H. Lee, H.-J. Cho, H.-Y. Kang, M. H. Rhee, and H.-J. Park, "Total saponin from Korean red ginseng inhibits thromboxane $\mathrm{A}_{2}$ production associated microsomal enzyme activity in platelets," Journal of Ginseng Research, vol. 36, no. 1, pp. 4046, 2012.

[13] S. M. Kamruzzaman, M. Endale, W. J. Oh et al., "Inhibitory effects of Bulnesia sarmienti aqueous extract on agonistinduced platelet activation and thrombus formation involves mitogen-activated protein kinases," Journal of Ethnopharmacology, vol. 130, no. 3, pp. 614-620, 2010. 
[14] H. S. Lee, S. D. Kim, W. M. Lee et al., "A noble function of BAY 11-7082: inhibition of platelet aggregation mediated by an elevated cAMP-induced VASP, and decreased ERK2/JNK1 phosphorylations," European Journal of Pharmacology, vol. 627, no. 1-3, pp. 85-91, 2010.

[15] J. Yang, J. Wu, H. Jiang et al., "Signaling through Gi family members in platelets: redundancy and specificity in the regulation of adenylyl cyclase and other effectors," The Journal of Biological Chemistry, vol. 277, no. 48, pp. 46035-46042, 2002.

[16] L. F. Brass, K. M. Wannemacher, P. Ma, and T. J. Stalker, "Regulating thrombus growth and stability to achieve an optimal response to injury," Journal of Thrombosis and Haemostasis, vol. 9, no. 1, pp. 66-75, 2011.

[17] A. Smolenski, "Novel roles of cAMP/cGMP-dependent signaling in platelets," Journal of Thrombosis and Haemostasis, vol. 10, no. 2, pp. 167-176, 2012.

[18] L. M. Ostertag, N. O’Kennedy, G. W. Horgan, P. A. Kroon, G. G. Duthie, and B. de Roos, "In vitro anti-platelet effects of simple plant-derived phenolic compounds are only found at high, non-physiological concentrations," Molecular Nutrition and Food Research, vol. 55, no. 11, pp. 1624-1636, 2011.

[19] L. M. Szewczuk and T. M. Penning, "Mechanism-based inactivation of COX-1 by red wine m-hydroquinones: a structureactivity relationship study," Journal of Natural Products, vol. 67, no. 11, pp. 1777-1782, 2004.

[20] A. Stojanovic, J. A. Marjanovic, V. M. Brovkovych et al., "A phosphoinositide 3-kinase-AKT-nitric oxide-cGMP signaling pathway in stimulating platelet secretion and aggregation," The Journal of Biological Chemistry, vol. 281, no. 24, pp. 16333-16339, 2006.

[21] F. Adam, A. Kauskot, P. Nurden et al., "Platelet JNK1 is involved in secretion and thrombus formation," Blood, vol. 115, no. 20, pp. 4083-4092, 2010. 


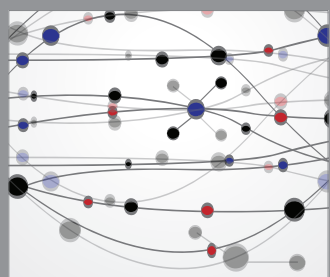

The Scientific World Journal
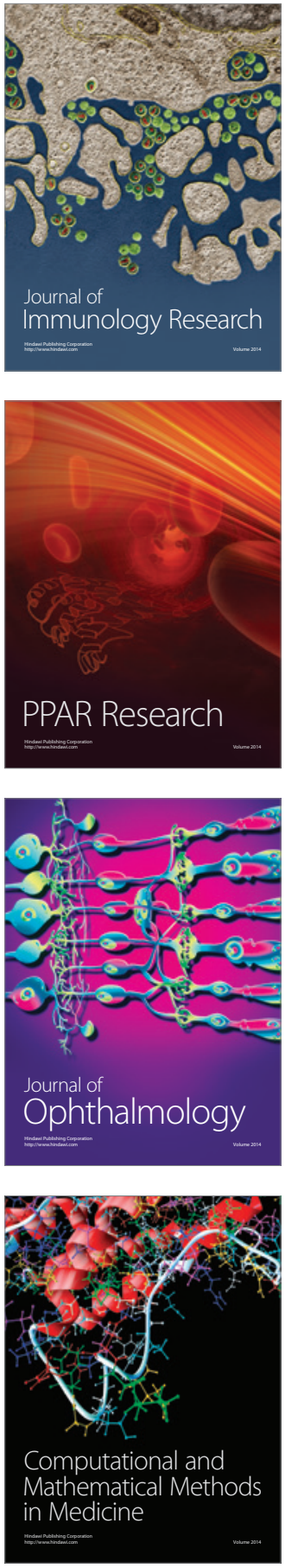

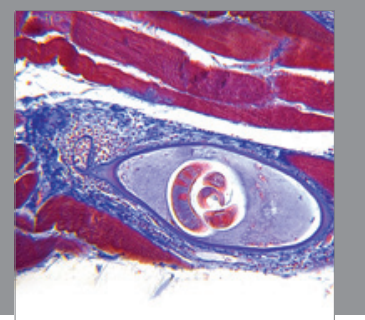

Gastroenterology

Research and Practice
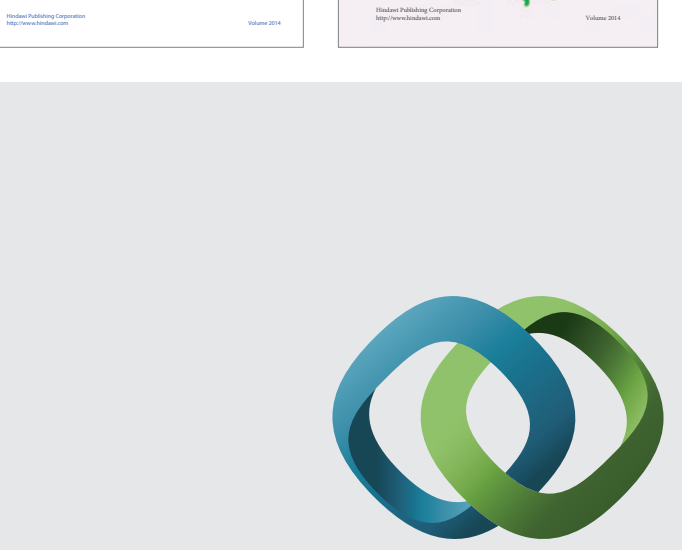

\section{Hindawi}

Submit your manuscripts at

http://www.hindawi.com
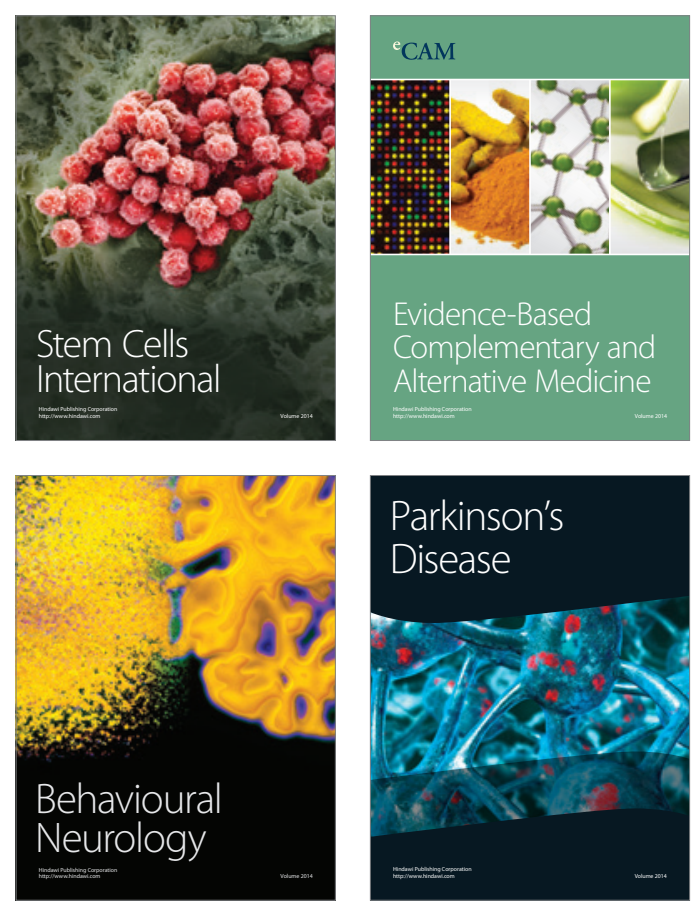

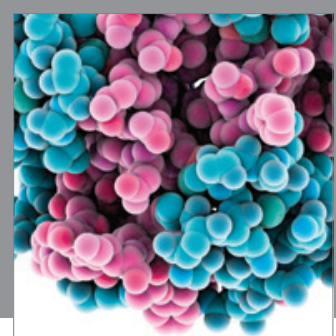

Journal of
Diabetes Research

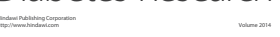

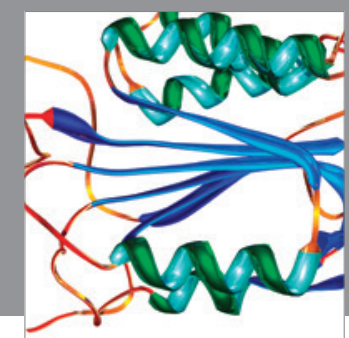

Disease Markers
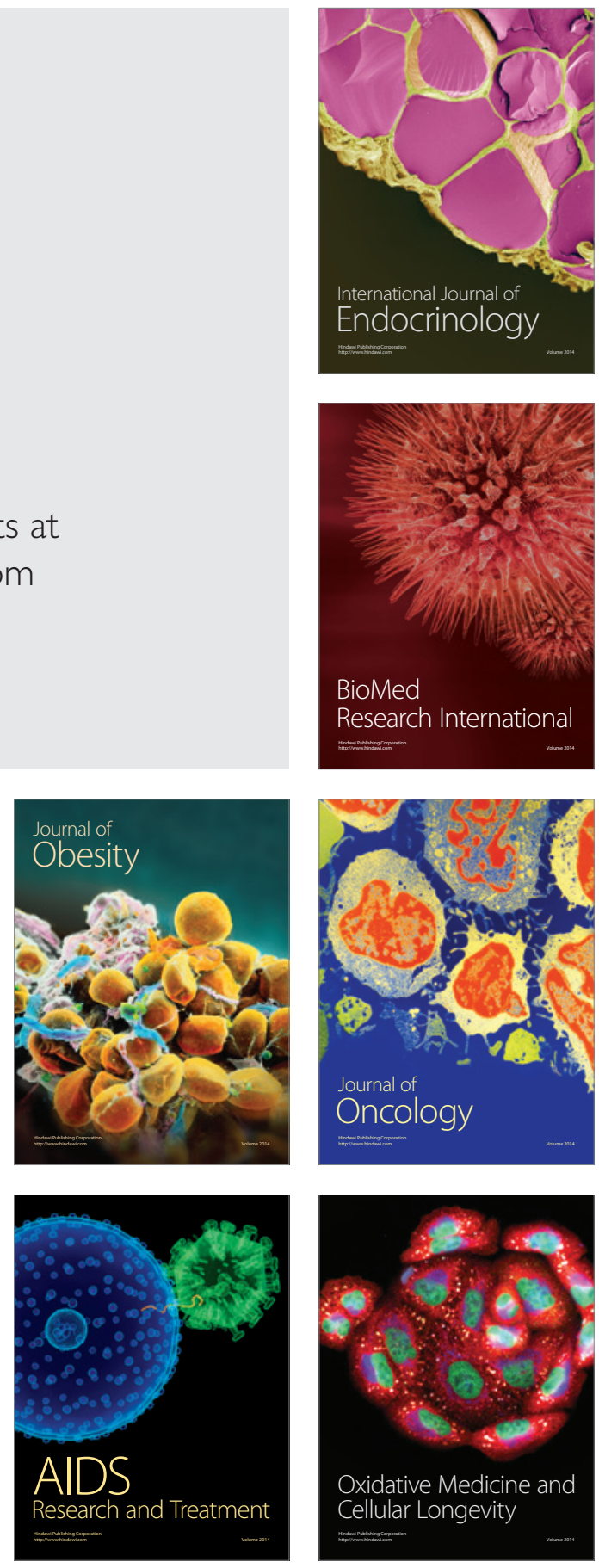